\title{
KALKULATOR FISIKA GERAK SATU DIMENSI BERBASIS ANDROID
}

\author{
Tutik Khotimah \\ Fakultas Teknik, Program Studi Teknik Informatika \\ Universitas Muria Kudus \\ Email: tutik.khotimah@umk.ac.id \\ F. Shoufika Hilyana \\ Fakultas Teknik, Program Studi Teknik Elektro \\ Universitas Muria Kudus \\ Email: farah.hilyana@umk.ac.id
}

\begin{abstract}
ABSTRAK
Fisika merupakan ilmu yang sebagian besar materinya dipelajari melalui pendekatan secara matematis. Salah satu materi yang dibahas dalam Fisika adalah Kinematika Gerak. Gerak benda dapat dijelaskan menggunakan sumbu koordinat. Gerak satu dimensi hanya menggunakan satu koordinat yaitu sumbu x atau sumbu y. Untuk memudahkan perhitungan dalam materi kinematika gerak satu dimensi, dibangun sebuah aplikasi Kalkulator Fisika Gerak Satu Dimensi. Kalkulator dirancang dengan flowchart dan desain input/output, sedangkan pengembangannya dengan software Sketchware. Dari pengujian black box, aplikasi ini dinyatakan dapat digunakan untuk menghitung Kecepatan dan Jarak pada gerak satu dimensi.
\end{abstract}

Kata Kunci: fisika kinematika, android, kalkulator, sketchware.

\begin{abstract}
Physics is a science that most of the material studied through a mathematical approach. One of the materials discussed in Physics is Motion Kinematics. Object motion can be explained using the coordinate axis. Single-dimensional motion uses only one coordinate that is the $x$-axis or $y$-axis. To facilitate calculations in one-dimensional motion kinematics, then built an application of Calculator Physics of OneDimensional Motion. The calculator is designed with flowchart and input / output design, while its development is with Sketchware software. From black box testing, this application can be used to calculate Speed and Distance in one-dimensional motion.
\end{abstract}

Keywords: kinematics physics, android, calculator, sketchware.

\section{PENDAHULUAN}

Saat ini smartphone menjadi perangkat teknologi informasi yang populer di masyarakat. Selain digunakan sebagai sarana telekomunikasi, perangkat ini juga dapat digunakan untuk mengakses berbagai aplikasi yang disediakan. Aplikasi tidak hanya dalam kategori hiburan saja, banyak aplikasi media pembelajaran yang dapat diakses melalui smartphone kapan pun dan dimana pun. Dengan aplikasi media pembelajaran, peserta didik lebih antusias untuk mendalami materi [1]. Beberapa media pembelajaran tersebut antara lain aplikasi media pembelajaran Fisika SMP kelas VII [2], media pembelajaran Gerak Parabola SMA [3], animasi Cahaya [4], media pembelajaran Hukum Newton [5]. Ada juga media pembelajaran Fisika untuk memperkuat karakter sains pada siswa [6]. Aplikasi-aplikasi tersebut dikembangkan berbasis android.

Berdasarkan data dari Internasional Data Corporation (IDC) pada tahun 2014 disimpulkan bahwa android memegang 84,4\% market share smartphone di seluruh dunia. Kesuksesan tersebut tidak terlepas dari sifatnya yang open source. Selain itu, aplikasi yang disediakan ada yang berbayar dan ada juga yang gratis sehingga pengguna dapat memilih aplikasi sesuai kebutuhan [7].

Fisika merupakan ilmu yang sebagian besar materinya dipelajari melalui pendekatan secara matematis [8]. Salah satu pokok bahasan yang tidak lepas dari persamaan matematis yaitu kinematika, di antaranya materi tentang gerak satu dimensi dan dua dimensi. Pada gerak satu dimensi, hanya mempunyai gerak pada garis lurus. Biasanya untuk mendeskripsikannya digunakan koordinat kartesius, sumbu-x untuk gerak horisontal dan sumbu-y untuk gerak vertikal [9]. Dalam memahami materi gerak, kesulitan yang dihadapi adalah dalam menggunakan rumus dalam perhitungan. Oleh karena itu, untuk memudahkan perhitungan, diperlukan alat bantu untuk menghitung.

Penelitian sebelumnya, aplikasi kalkulator Fisika Pencerminan berbasis android dikembangkan dengan menggunakan Sketchware [10]. Aplikasi ini digunakan untuk melakukan perhitungan dalam memecahkan kasus pada cermin datar, cermin cekung, dan cermin cembung. Sejalan dengan penelitian tersebut, penelitian ini membahas 
tentang pembangunan aplikasi berbasis android yang dapat digunakan untuk memudahkan perhitungan dalam Fisika khususnya pada materi kinematika gerak satu dimensi. Aplikasi dibangun dengan software Sketchware, yang berjalan pada platform Android.

Sketchware membuat aplikasi android di smartphone, membawa imajinasi untuk hidup, mengembangkan program, menghimpun, dan menjalankan dengan teratur pada device. Tidak perlu banyak pengalaman progamming sebelumnya, koneksi mudah untuk membuat logic pada aplikasi ini. Project selesai secara otomatis diterjemahkan ke dalam Java dan XML, project secara penuh sesuai dengan sistem operasi android [11].

\section{METODE PENELITIAN}

Penelitian ini adalah penelitian rekayasa perangkat lunak (research and development). Metode yang digunakan adalah Software Development Life Cycle (SDLC). Tahapan penelitian sebagai berikut:

a. Pengumpulan Data

Pada tahap ini dilakukan pengumpulan data berupa materi Kinematika Gerak 1 Dimensi dan rumus-rumus yang terkait dengan materi tersebut.

b. Analisa

c. Setelah dilakukan pengumpulan data, tahap berikutnya adalah melakukan analisa kebutuhan sistem.

d. Perancangan

e. Pada tahap ini dilakukan perancangan sistem dengan menggunakan flowchart. Selain itu juga dilakukan perancangan antarmuka (input/output).

f. Implementasi

g. Aplikasi dibangun dengan software Sketchware yang dapat berjalan di Android. Pada Sketchware terdapat 2 bagian, yaitu: View dan Logic. Pada tahap implementasi, dilakukan penyusunan View dan Logic sesuai perancangan yang telah dibuat.

Kerangka pemikiran penelitian ini dapat dilihat pada gambar 1.

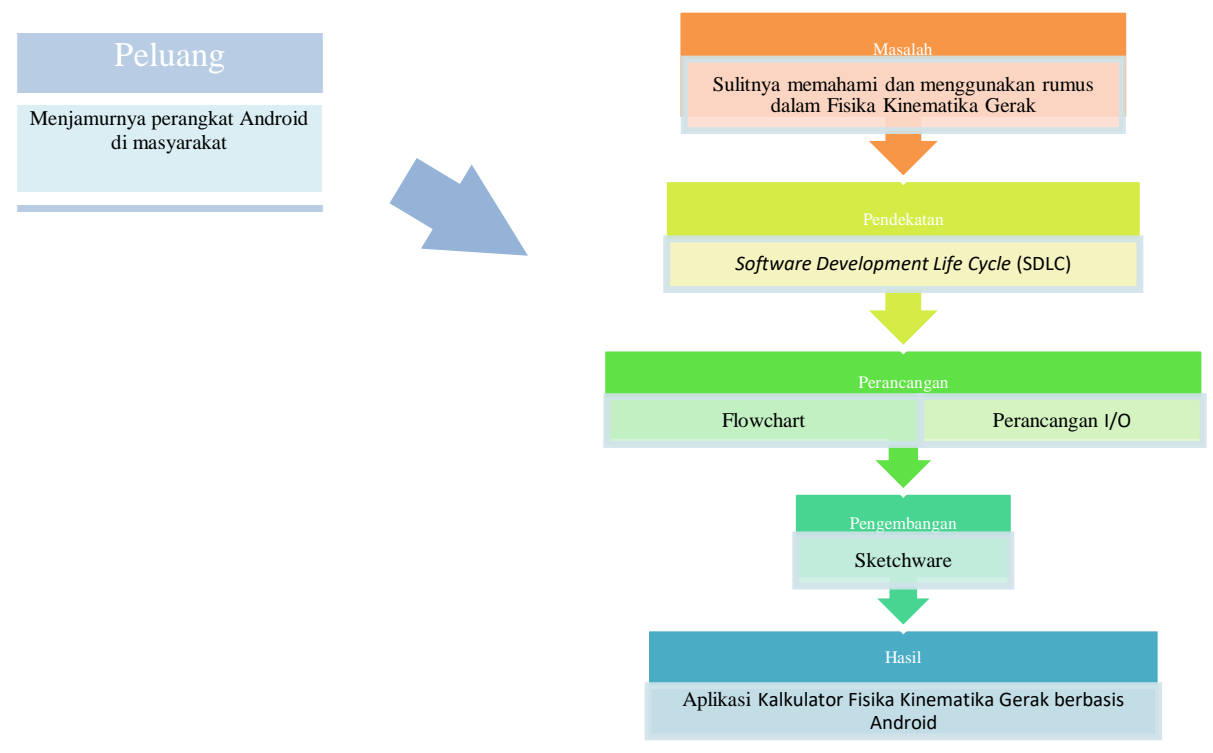

Gambar 1. Kerangka Pemikiran

\section{HASIL PENELITIAN DAN PEMBAHASAN}

\subsection{Flowchart}

Kalkulator Fisika Gerak 1 Dimensi dirancang dengan flowchart. Berikut ini flowchart Kalkulator Fisika Gerak 1 Dimensi yang dapat dilihat pada gambar 2. 


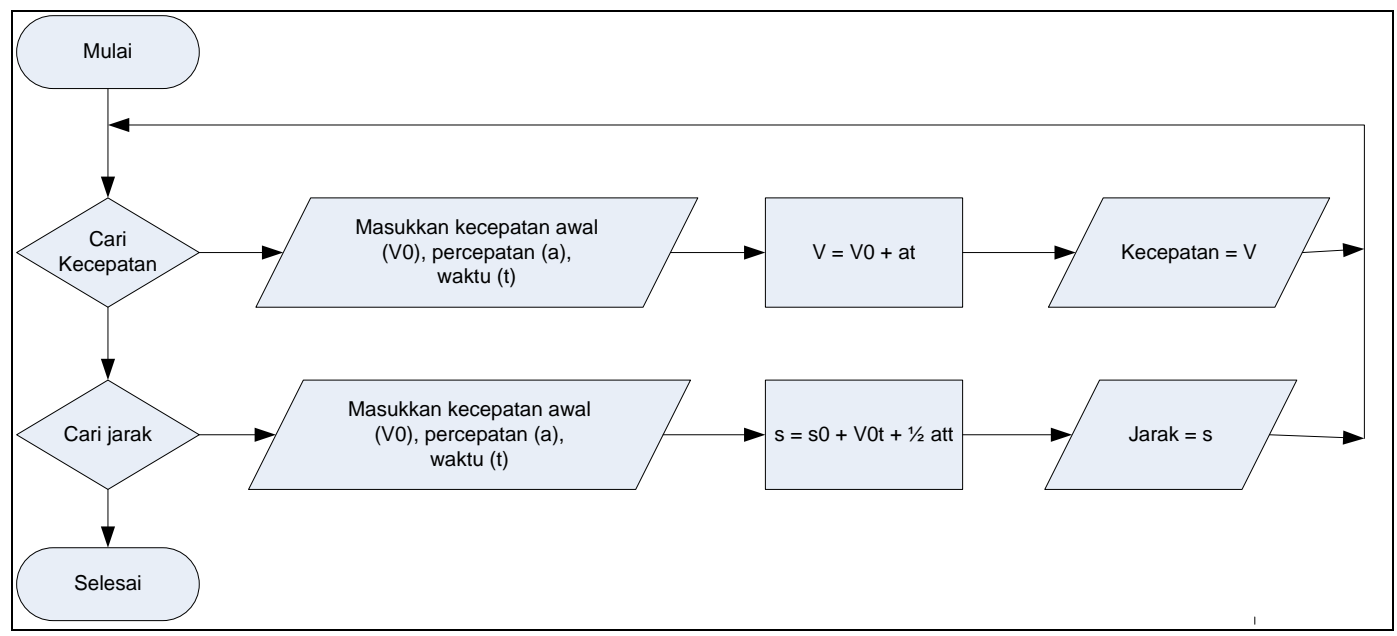

\section{Gambar 2. Flowchart Kalkulator Fisika Gerak 1 Dimensi}

Menu yang disediakan pada aplikasi terdiri dari 2 pilihan, yaitu menu untuk mencari Kecepatan dan menu untuk mencari Jarak. Pada pilihan Cari Kecepatan, pengguna diminta untuk memasukkan nilai kecepatan awal ( $\left.\mathrm{V}_{0}\right)$, nilai percepatan (a), dan nilai waktu. Dari masukan ini, dilakukan penghitungan nilai kecepatan (V) dengan menggunakan persamaan 1.

$V=V_{0}+a t$

Pada pilihan Cari Jarak, pengguna diminta untuk memasukkan nilai kecepatan awal $\left(\mathrm{V}_{0}\right)$, nilai percepatan (a), dan nilai waktu. Dari masukan ini, dilakukan penghitungan nilai jarak (s) dengan menggunakan persamaan 2.

$s=s_{0}+V_{0}+1 / 2 a t^{2}$

\subsection{Implementasi}

Kalkulator Fisika Kinematika Gerak 1 Dimensi dibangun dengan menggunakan Sketchware. Pada Sketchware terdiri dari 2 bagian, yaitu: View dan Logic. Tampilan pada View ditunjukkan pada gambar 3, sedangkan tampilan pada Logic ditunjukkan pada gambar 4.

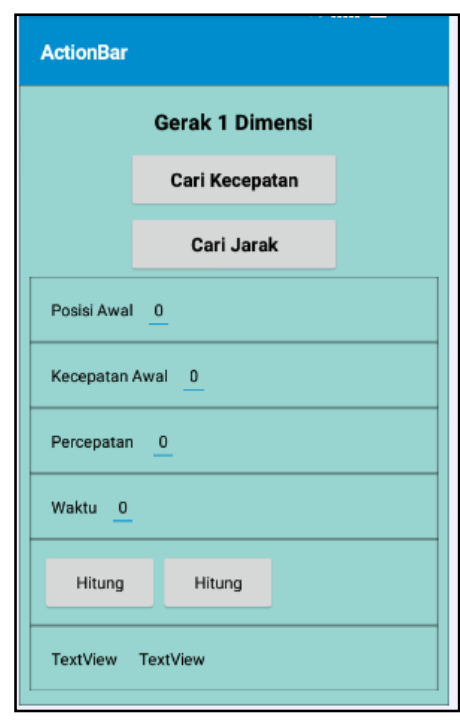

\section{Gambar 3. Tampilan View pada Kalkulator Fisika Gerak 1 Dimensi}

View pada Kalkulator Fisika Gerak 1 Dimensi terdiri dari 3 Widgets antara lain: TextView sebanyak 7 buah, Button sebanyak 4 buah, dan EditView sebanyak 4 buah. Masing-masing dapat dilihat pada gambar 3. 


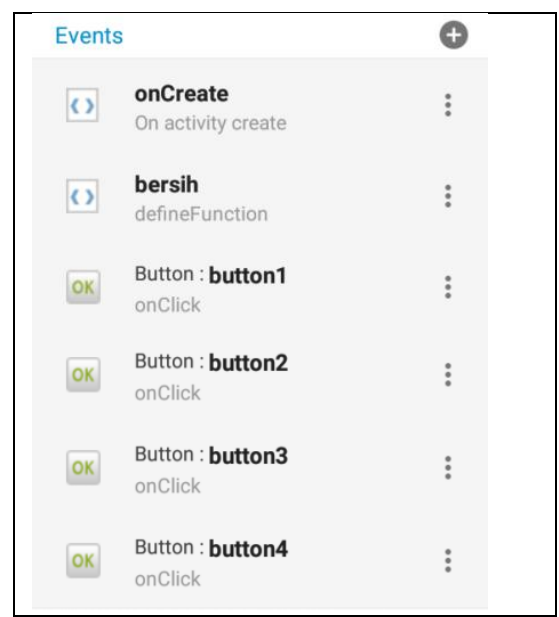

\section{Gambar 4. Tampilan Logic pada Kalkulator Fisika Gerak 1 Dimensi}

Logic pada Kalkulator Fisika Gerak 1 Dimensi terdiri dari 6 Event, yaitu: (1) on activity create, (2) defineFunction bersih, (3) buttonl onClick, (4) button 2 onClick, (5) button3 onClick, dan (6) button4 onClick. Pada Event yang pertama terdapat pemanggilan Function bersih, di mana pada Function tersebut berisi setting-an awal terhadap Widgets yang ada pada View. Event ke-3 berisi perintah untuk menampilkan masukan yang diperlukan untuk mencari Kecepatan, sedangkan Event ke-4 berisi perintah untuk menampilkan masukan yang diperlukan untuk mencari Jarak. Ada pun Event ke-5 digunakan untuk menghitung Kecepatan dan Event ke-6 digunakan untuk menghitung jarak. Tampilan Logic pada Event ke-5 ditunjukkan pada gambar 5, sedangkan Event ke-6 ditunjukkan pada gambar 6.

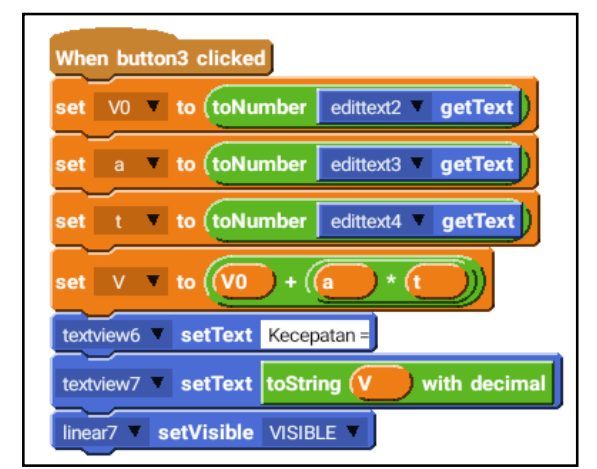

\section{Gambar 5. Tampilan Event Button3 onClick}

Pada Event button3 onClick, dilakukan setting nilai untuk variabel-variabel V0, a, t, dan V. Variabel V0 berisi nilai masukan pada EditText2, demikian juga dengan variabel a dan variabel t berisi nilai masukan pada EditText3 dan EditText 4. Sedangkan variabel V merupakan hasil perhitungan yang merupakan penerapan dari persamaan 1 .

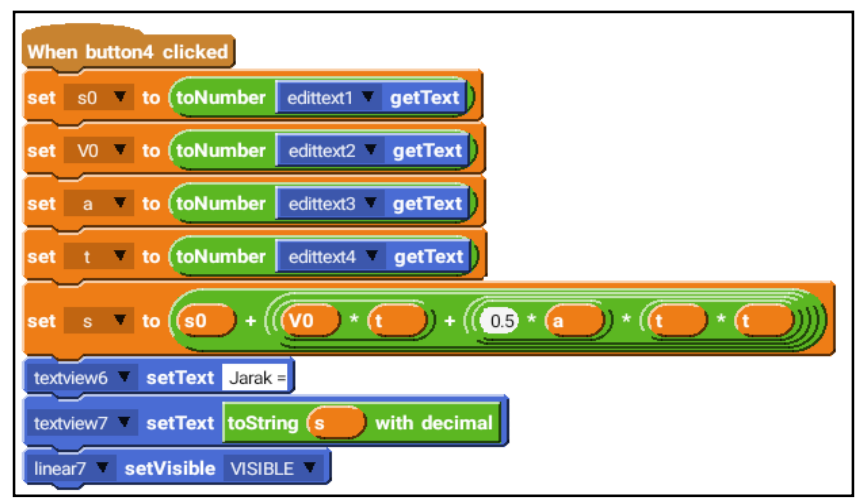

Gambar 6. Tampilan Event Button4 onClick 
Pada Event button4 onClick, dilakukan setting nilai untuk variabel-variabel s0, V0, a, t, dan s. Variabel s0 berisi nilai masukan pada EditText1, demikian juga dengan variabel V0, variabel a dan variabel $\mathrm{t}$ berisi nilai masukan pada EditText2, EditText3 dan EditText 4. Sedangkan variabel s merupakan hasil perhitungan yang merupakan penerapan dari persamaan 2 .

\subsection{Pengujian}

Pengujian yang dilakukan pada Kalkulator Fisika Gerak 1 Dimensi ini adalah pengujian BlackBox. Pengujian dilakukan untuk mengetahui apakah rumus yang digunakan dalam aplikasi sudah sesuai atau belum. Ada dua pengujian yang dilakukan. Pengujian pertama dilakukan untuk menguji kecepatan dan pengujian kedua digunakan untuk menguji jarak. Daftar pengujian dapat dilihat pada tabel 1, sedangkan hasil pengujian dapat dilihat pada gambar 7.

Tabel 1. Pengujian kalkulator fisika gerak 1 dimensi

\begin{tabular}{|c|c|c|c|c|}
\hline No & Jenis Pengujian & Perhitungan Manual & Hasil & Kesimpulan \\
\hline 1 & $\begin{array}{l}\text { Kecepatan } \\
\text { Kecepatan Awal = } 10 \\
\text { Percepatan }=10 \\
\text { Waktu }=2\end{array}$ & $\begin{array}{l}\text { Kecepatan = Kecepatan Awal + } \\
\text { Percepatan * Waktu } \\
=10+10 * 2 \\
=30\end{array}$ & $\begin{array}{c}\text { Gambar } \\
7 \text { (a) }\end{array}$ & Sesuai \\
\hline 2 & $\begin{array}{l}\underline{\text { Jarak }} \\
\text { Posisi Awal = 5 } \\
\text { Kecepatan Awal = } 10 \\
\text { Percepatan = } 10 \\
\text { Waktu = } 2\end{array}$ & $\begin{array}{l}\text { Jarak }=\text { Posisi Awal + Kecepatan Awal * } \\
\text { Waktu }+0,5 * \text { Percepatan * Waktu ^ } 2 \\
=5+10 * 2+0,5 * 10 * 2 \wedge 2 \\
=45\end{array}$ & $\begin{array}{c}\text { Gambar } \\
7 \text { (b) }\end{array}$ & Sesuai \\
\hline
\end{tabular}

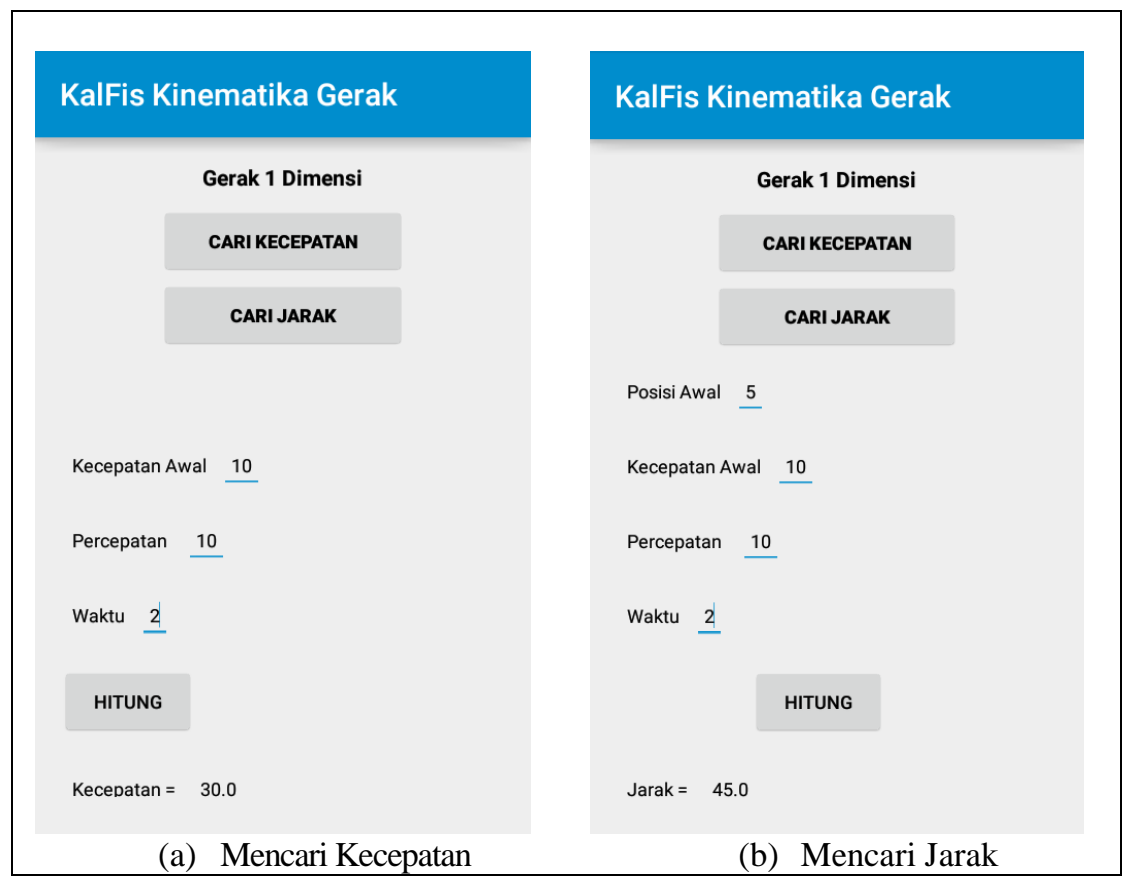

Gambar 7. Kalkulator Fisika Gerak 1 Dimensi Ketika Dijalankan 


\section{KESIMPULAN DAN SARAN}

Dari pembahasan di atas dapat disimpulkan bahwa: (1) telah dihasilkan Kalkulator Fiisika Gerak 1 Dimensi yang dapat berjalan pada platform Android (2) kalkulator dapat digunakan untuk mencari nilai Kecepatan dan Jarak pada gerak 1 dimensi (3) inputan pada kalkulator hanya berupa angka, belum ada konversi satuan terhadap masingmasing variabel.

Saran untuk penelitian selanjutnya antara lain: (1) kalkulator dapat dikembangkan untuk gerak 2 dimensi dan 3 dimensi (2) penambahan fitur pada kalkulator berupa konversi satuan terhadap masing-masing variabel yang ada dalam gerak.

\section{DAFTAR PUSTAKA}

[1] Gideon S. 2016. "Peran Media Pembelajaran Fisika Gerak bagi Pelajar dan Mahasiswa”. JDP. Vol. 9 (3), pp 163-175.

[2] Nurohimah, S., Wahyudin, dan Partono. 2014. "Perancangan Aplikasi Media Pembelajaran Fisika untuk SMP Kelas VII Berbasis Android”. Jurnal Algoritma Sekolah Tinggi Teknologi Garut. Vol. 11(1), pp. 1-10.

[3] Marhadini, S.A.K., Akhlis, I., dan Sumpono, I. 2017. "Pengembangan Media Pembelajaran Berbasis Android pada Materi Gerak Parabola untuk Siswa SMA”. Unnes Physics Education Journal. Vol. 6 (3), pp. 38-43.

[4] Anggraeni, R.D., Kustijono, R. 2013. "Pengembangan Media Animasi Fisika pada Materi Cahaya dengan Aplikasi Flash Berbasis Android”. Jurnal Pendidikan Fisika dan Aplikasinya (JPFA). Vol. 3(1), pp. 11-18.

[5] Arif, I.N., Harsani, P., dan Qur'ania, A. 2017. "Media Pembelajaran Hukum Newton Berbasis Android". Program Studi Ilmu Komputer-FMIPA Universitas Pakuan.

[6] Fatimah, S. Murti, Y. 2014. "Pengembangan Media Pembelajaran IPA-Fisika Smartphone Berbasis Android sebagai Penguat Karakter Sains Siswa". Jurnal Kaunia. Vol. X(1) pp. 59-64.

[7] Oktiana, G.D. 2014. "Pengembangan Media Pembelajaran Berbasis Android dalam Bentuk Buku Saku Digital untuk Mata Pelajaran Akuntansi Kompetensi Dasar Membuat Ikhtisar Siklus Akuntansi Perusahaan Jasa di Kelas XI MAN 1 Yogyakarta Tahun Ajaran 2014/2015”. Skripsi pada Universitas Negeri Yogyakarta.

[8] Rezeki, S. dan Ishafit. 2017. "Pengembangan Lembar Kerja Siswa (LKS) Berbantuan Media Simulasi dengan Modellus untuk Pembelajaran Kinematika di Sekolah Menengah Atas”. Seminar Nasional Pendidikan Fisika III Program Studi Pendidikan Fisika, FKIP, UNIVERISTAS PGRI Madiun, Madiun, 15 Juli 2017 pp. 130133.

[9] Jeffery, D.J. 2008. “One-Dimensional Kinematics”. Department of Physics, University of Idaho, Moscow, U.S.A. Lecture.

[10] Khotimah, T., Hilyana, F.S. 2017. "Aplikasi Kalkulator Fisika Pencerminan Berbasis Android”. Prosiding SNATIF ke-4 Fakultas Teknik Universitas Muria Kudus. pp 15-24.

[11] Sketchware. 2016. "Sketchware - IDE in Your Pocket.html". 